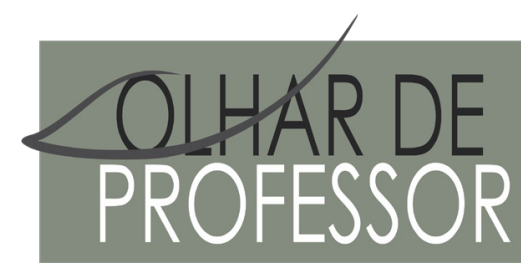

DOI: 10.5212/OLHARPROFR.v.22.0012

\title{
A CULTURA DO BRINCAR E A PRESENÇA DA MIMESE, DO DESVIO E DA REPETIÇÃO NAS MEMÓRIAS DE INFÂNCIA DE MIGRANTES DE SINOP-MATO GROSSO
}

\author{
THE CULTURE OF PLAY AND THE PRESENCE OF MIMESE, DEVIANCE AND REPETITION IN CHILDHOOD \\ MEMORIES OF MIGRANTS FROM SINOP-MATO GROSSO
}

\section{LA CULTURA DEL JUEGO E LA PRESENCIA DE LA MIMESE, DESVIACIÓN Y DE LA REPETICIÓN EN MEMORIAS DE LA INFANCIA DE LOS MIGRANTES DE SINOP-MATO GROSSO}

JOSIANE BROLO ROHDEN ${ }^{*}$

\begin{abstract}
Resumo: Este trabalho propõe, a partir de memórias da infância numa perspectiva histórico-fenomenológica, oferecer uma reflexão sobre a cultura do brincar e a presença da mimese, do desvio e da repetição nas brincadeiras de infância. Trata-se de implicações construídas em uma pesquisa realizada com narrativas de memórias de migrantes de Sinop-MT, que vivenciaram suas infâncias no processo de colonização da cidade, em especial entre os anos de 1973 a 1986. A intenção é fomentar a discussão de que independente de tempos e espaços, no passado e no presente, as crianças brincam, aprendem a brincar, inventam, criam e fazem do brincar o verbo do seu viver e, deste modo, quando brincam, criam seus próprios mundos, suas culturas infantis, são autores e autoras das próprias histórias. Contudo, o trabalho estabelece um diálogo entre a ciência e a poesia de Manoel de Barros, uma vez que a literatura do poeta contribui para com um olhar das memórias da infância, enquanto poiesis de vida, enquanto artes de se viver.
\end{abstract}

Palavras-chave: Memórias; Infância; Brincadeiras.

\begin{abstract}
This paper proposes from childhood memories, in a historical-phenomenological perspective, to offer a reflection on the culture of play and the presence of mimesis, deviance and repetition in childhood games. These are implications constructed in a research conducted with narratives of memories' migrants from Sinop, Mato Grosso state, who experienced their childhood in the colonization process of the city, especially between the years 1973 to 1986. The intention is to foster the discussion that independent of times and spaces, in the past and in the present, the children play, learn to play, invent, create and make playing the verb of their living and, thus, when they play, create their own worlds, their cultures children, are authors of their own histories. Finally, the work establishes a dialogue between the science and poetry of Manoel de Barros, since the literature of the poet contributes to a glance of childhood memories, as poiesis of life, as the arts of living.
\end{abstract}

Keywords: Memories; Childhood; Play.

Resumen: Este trabajo propone desde las memorias de la infancia, en una perspectiva histórico-fenomenológica, para ofrecer una reflexión sobre la cultura del juego y la presencia de mimesis, desviación y repetición en los juegos infantiles. Estas son implicaciones construidas en una investigación realizada con narrativas de memorias de los migrantes de Sinop-MT, que experimentaron sus infancia en el proceso de colonización de la ciudad, especialmente entre los años de 1973 a 1986. La intención es fomentar la discusión que independiente de los tiempos y espacios, en el passado y en el presente, los niños juegan, aprenden a jugar, inventan, crean y hacen del jugar el verbo de sus vidas y, por lo tanto, cuando juegan, crean sus propios mundos, sus culturas infantiles, son autores y autoras de sus propias historias. Por último, la obra establece un diálogo entre la ciencia y la poesía de Manoel de Barros, ya que la literatura del poeta contribuye a una mirada de memorias de la infancia, como poiesis de la vida, como las artes de vivir.

Palabras-clave: Memorias; Infancia; Juegos.

*Doutora em Educação. Professora da Universidade Federal de Rondônia - UNIR. josiane.rohden@unir.br 


\title{
A CULTURA DO BRINCAR E A PRESENÇA DA MIMESE, DO DESVIO E DA REPETIÇÃO NAS MEMÓRIAS DE INFÂNCIA DE MIGRANTES DE SINOP-MATO GROSSO
}

INTRODUÇÃO: UMA PESQUISA, UM OLHAR DE PÁSSARO

\begin{abstract}
Por viver muitos anos dentro do mato - Moda ave, O menino pegou um olhar de pássaro -

Contraiu visão Fontana.

Por forma que ele enxergava as coisas por igual: como os pássaros enxergam.

Manoel de Barros, 2010.
\end{abstract}

Pegar um olhar de pássaro. Contrair visão Fontana. Olhar para prender a visão no pequeno, naquilo que não costumamos ver, que muitas vezes nos passa despercebidos. Olhar para os detalhes, para as coisas aparentemente banais. Educar o olhar - sensibilizá-lo. Enxergar as coisas como pássaros, talvez este seja um dos grandes desafios de um pesquisador na contemporaneidade. Olhar amplo e ao mesmo tempo minucioso. Olhar que vê algo a mais, em singularidades, não em verdades. Deste modo, um caminho metodológico não se restringe a visão cartesiana de métodos, amostras, dados, análises, resultados, etc. Mas, também de olhares. Olhares-aves! Olhares binômios! Olhares-azuis! Uma vez que "as coisas não querem mais ser vistas por pessoas razoáveis. Elas desejam ser olhadas de azul - Que nem uma criança que você olha de ave” (BARROS, 2010, p. 208).

Nessa construção de educar um olhar azul, deparo-me com a necessidade fenomenológica de ter uma atitude de pesquisadora ${ }^{1}$ que não se isenta, não se afasta do mundo, mas, que se integra, se interliga junto aos sujeitos da pesquisa em comunhão com os mesmos e com o lócus de pesquisa (SANTOS, 2017, p. 1), porque sinto-me pertencida a todo o processo, a toda experiência que vivi a partir das memórias que eu ouvi dos sujeitos que constroem esse estudo. Deste modo, esta é uma composição de memórias que sugerem uma das muitas possibilidades de se narrar a história, corroborando com o que sugere Pesavento (1997, p. 117), quando diz que:

A clássica maneira de ser da história - construção de um saber como estatuto de ciência e objetivando a verdade - é substituída por outra, na qual as fontes, matéria prima da história, são consideradas como "indiciárias" daquilo que podia ter sido e com as quais o historiador constrói a sua versão. Neste caso, a história, se reveste de uma função de criação, ao selecionar documentos, compor um enredo, desvendar uma intriga, recuperar significados.

Com isso, há muitos descaminhos e trilhas percorridas repletas de curvas que se fazem presentes nesse trabalho, o qual apresenta algumas discussões de uma pesquisa que trata de uma investigação historiográfica sobre o brincar enquanto produção cultural da infância. Para tal, a pesquisa foi desenvolvida com sujeitos que vivenciaram suas infâncias na cidade de Sinop - MT, durante o processo de fundação e migração, tendo como temporalidade histórica os anos de 1973 a 1986. Nesse âmbito, a escrita deste trabalho foge dos padrões ainda tão insistentemente técnicos da ciência moderna, buscando um novo olhar a partir de uma escrita poético-stricto sensu (STRECK, 2017), para "convidar a Academia a se desinstalar e ousar mais em termos de linguagem” (STRECK, 2017, p. 1). Assim, ciência e poesia se entrelaçam a todo tempo, como manifestação da vida como obra de arte (DIAS, 2011), pois, a ciência por si, não dá conta de dizer sozinha da vida, daquilo que pulsou e que pulsa. A vida é arte, criação, potência e "como fenômeno estético a existência ainda nos é suportável, e por meio da arte nos são dados olhos e mãos e, sobretudo, boa consciência, para poder fazer de nós mesmos um tal fenômeno" (NIETZSCHE, 2001, p. 132).

Nesse cenário, a pesquisa se aporta numa perspectiva histórico-fenomenológica, na qual entende toda produção histórica enquanto poiesis humana, ou seja, enquanto criação do humano que não se separa da natureza, mas, se faz junto dela. Assim, como recursos de pesquisa, entendidos como vestígios da criação humana, o trabalho utiliza-se de documentos históricos adquiridos em acervos pessoais e públicos, fotografias e narrativas de memórias construídas com os sujeitos que vivenciaram a infância na temporalidade investigada. Deste modo, para atender as normativas éticas da pesquisa², alguns trechos

\footnotetext{
${ }^{1}$ Este trabalho é parte de uma pesquisa de Doutorado, financiada pela CAPES- PDSE, desenvolvida na Universidade Federal de Mato Grosso - UFMT e na Loyola University Chicago, USA.

${ }^{2}$ Esta pesquisa foi submetida ao Comitê de Ética em Pesquisa e encontra-se em situação Aprovada, sob CAAE: 54769416.2.0000.5690. Desta forma, a pesquisadora comprometeu-se em seguir as normas da Resolução 466/2012.
} 
das narrativas ${ }^{3}$ serão apresentados nesse trabalho, os quais serão identificados por "MIGRANTE 1, 2, 3, etc.” para se referir aos adultos migrantes que viveram suas infâncias no lócus estudado.

Contudo, para fins de apresentação do lugar investigado, faz-se importante mencionar que a cidade de Sinop foi fruto de uma política de integração nacional da Amazônia brasileira durante a Ditadura Militar no Brasil (1964-1985), quando o governo federal, depois de algumas tentativas falhas de uma colonização estatal, vendeu uma grande área de terra para uma empresa privada. Assim, Sinop nasceu a partir de um projeto de colonização privada empreendido pela empresa Colonizadora - Sociedade Imobiliária do Noroeste do Paraná - Sinop S. A, a qual adquiriu uma extensa área na região norte de Mato Grosso, denominada Gleba Celeste, a 500 km da capital Cuiabá, na época pertencente ao município de Chapada dos Guimarães, conforme Portaria do INCRA No 1.553/1972 (PANOSSO NETTO, 2000).

Nesse contexto, muitos migrantes - colonos, investidores individuais ou empresariais, entusiasmados pelas propagandas de tal momento histórico e pelos incentivos do Governo Federal migraram para o novo espaço na busca de um futuro mais promissor economicamente. A maioria dos migrantes vieram da Região Sul do país, atraídos principalmente pelo baixo valor das terras e pela publicidade feita para estimular e deslumbrar a possibilidade de viver num 'Eldorado' onde "tudo que se plantava, se colhia" (MIGRANTE 8, Depoimento 2012).

A forte propaganda na região a ser povoada, possuía a marca do progresso, idealizavam um 'Eldorado' cuja esperança tomava forças, os sonhos se projetavam e os desejos de futuro se reafirmavam. Como explica Guimarães Neto (2002, p. 149), tais discursos pontuados no progresso apresentados nas propagandas "era uma marca indelével, presente em todos os lugares por onde se passava, direcionando condutas humanas, projetando a esperança no amanhã, refazendo a todo o momento o mito do possível”.

Contudo, tal processo de migração para o Centro-Oeste, explicado por Joanoni Neto (2012, p. 6), foi, para muitos lavradores, uma peregrinação em busca da terra prometida. Eles idealizavam as propagandas que os atraíram para a solução de seus problemas. Nas palavras do autor, "sua chegada ao novo destino foi o ingresso ao lugar do sonho, da utopia, constituído dos anseios que carregavam: possuir a terra, trabalhar para si, fugir da proletarização, mas a propaganda que afirmava serem esses os locais onde a concretização desse sonho seria possível”.

Nesse espaço que se formava a cidade de Sinop, haviam crianças que estavam e participaram do processo de colonização, elas eram levadas às ruas para recepcionar autoridades, para se apresentar em eventos culturais, em desfiles cívicos, carregando inclusive mensagens que culminavam com as propagandas que divulgavam a cidade "Sinop: um passo da conquista na Amazônia”. Além disso, de acordo com os depoimentos e os vestígios históricos encontrados, eram nas crianças que a esperança de futuro estava depositada.

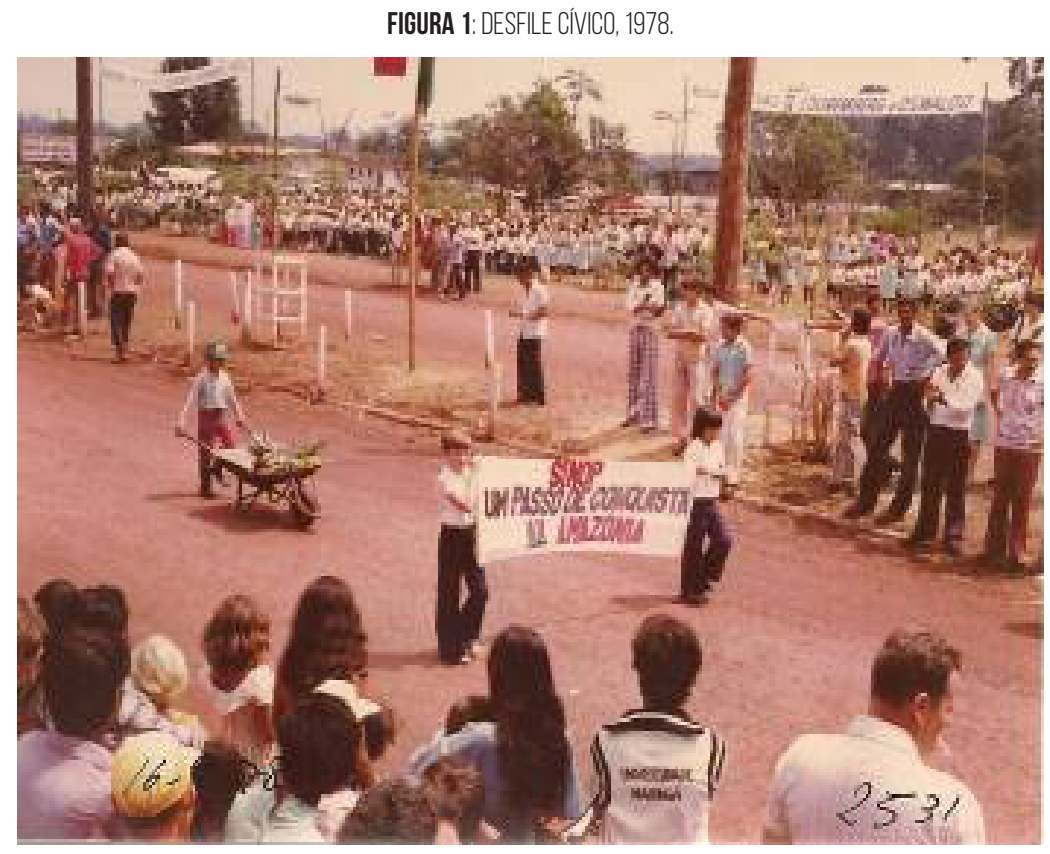

FONTE: COLONIZADORA SINOP, ACERVO PESSOAL, २०17.

\footnotetext{
${ }^{3}$ Todas as narrativas foram devidamente consentidas e documentadas em TCLE, como solicitado pelo CEP.
} 


\section{A CULTURA DO BRINCAR E A PRESENÇA DA MIMESE, DO DESVIO E DA REPETIÇÃO NAS MEMÓRIAS DE INFÂNCIA DE MIGRANTES DE SINOP-MATO GROSSO}

Entretanto, a percepção apresentada pela história oficial é de que as crianças eram figurantes de uma história, de uma sociedade, e não produtoras de cultura e da própria história. Não há uma visibilidade justa da infância enquanto sujeitos participantes de todo um processo de constituição de uma cidade.

É nesse cenário que entendemos a criança do passado como coautora da história e como historiadores de si. Nesse sentido, os narradores de suas histórias - meninos e meninas do/no m/Mato ${ }^{4}$, sujeitos desta pesquisa, ao narrar suas experiências nos trazem de modo singular e peculiar suas experiências formativas, assim como suas memórias de um universo infantil repleto de imaginação, de invenção, de construção, de artes de fazer, de bricolagens (CERTEAU, 1998), feitas a partir das suas relações com o outro, com a natureza, com os restos, com os sonhos de infância. As narrativas soam como gestos de libertação, de fluidez da vida que pulsa, da infância não linear, não cronometrada por um tempo exterior ao sujeito. Deste modo, cada migrante ao narrar suas experiências “ia até a infância e voltava” (BARROS, 2010, p. 42). Diante do exposto, Benjamin (2002, p. 101) nos diz que "o adulto, ao narrar uma experiência, alivia o seu coração dos horrores, goza duplamente uma felicidade. A criança volta a criar para si todo o fato vivido, começa mais uma vez do início”.

Neste sentido, como enfatizado nos versos de Manoel de Barros, "o menino de ontem me plange” (BARROS, 2010, p. 331) ou seja, somos habitados pela criança que fomos, fruto da experiência vivida possível de ser narrada a partir de nossas memórias, e portanto, toda vez que passeamos por nossa história que se faz inversa, no instante do presente (CERTEAU, 1982), reaparece como um 'enigma' o "menino que resta de nós” (BARROS apud MÜLLER, 2010, p. 145), guardado como em um baú de brinquedos em nossos corpos, em que vamos soprando a poeira, para melhor percebê-lo, para sentir toda a potência histórica que ele carrega, pois ele está cheio das nossas experiências vividas. O nosso corpo é o baú vivo da nossa história em sincronia e diacronia (AGAMBEN, 2005) com o tempo, com o mundo:

Eu não amava que botassem data na minha existência. A gente usava mais era encher o tempo. Nossa data maior era o quando. O quando mandava em nós [...] hoje eu estou quando infante. Eu resolvi voltar quando infante por um gosto de voltar. Como quem aprecia ir às origens de uma coisa ou de um ser. Então agora eu estou quando infante (BARROS, 2008, p. 113, grifos meus).

Deste modo, nos meninos e meninas que restam em cada um dos sujeitos de pesquisa quando ao narrar suas infâncias no/do m/Mato, o brincar surge "ali, pertinho" (BARROS, 2010, p. 162) como se o "tempo estivesse sido amarrado no poste" (BARROS, 2010) e então todo o resto "fosse só distância” (BARROS, 2010, ibdem). Sob essa ótica de memórias crianceiras ${ }^{5}$, analisadas numa perspectiva histórico-poética ${ }^{6}$, busca-se discutir a cultura do brincar e a presença da mimese, do desvio, da repetição nas experiências das brincadeiras de infância dos migrantes pesquisados. Nesse contexto, o brincar é compreendido numa perspectiva da produção histórica, social e cultural da infância e numa dimensão filosófica, que concebe o brincar enquanto experiência humana, enquanto retorno do vivido, "no limite da história e da lenda” (BACHELARD, 2009, p. 85).

No entanto, intenta-se propor uma história menor ${ }^{7}$, qual fomenta que os sujeitos pesquisados, meninos e meninas do/no m/Mato, trazem em suas narrativas imagens de uma história-ficção (CERTEAU, 1982), uma história que é impossível de se retornar ao modo como exatamente aconteceu, mas, possível de se remexer num território de pertencimento e de desterritorialização do ser, através do movimento trazido pelas “memórias fósseis” (BARROS, 2010). Memórias que se aproveitam da ocasião (CERTEAU, 1998). “A ocasião é um nó [...]. Não é um fato destacável de volta que o produz” (CERTEAU, 1998, p. 159). Para o autor, “a ocasião é aproveitada, não criada” (CERTEAU, 1998, p. 162). Deste modo, as memórias fósseis de Manoel de Barros assim como as nossas próprias memórias, se aproveitam de um “momento equilibrista e tático, o instante da arte" (CERTEAU, 1998, idem):

\footnotetext{
${ }^{4}$ As expressões no/do m/Mato é para ressaltar o mato enquanto espaço de floresta e Mato enquanto estado de Mato Grosso, os adultos que viveram suas infâncias no espaço investigado, a cidade de Sinop, serão assim mencionados em alguns momentos nesse trabalho.

${ }^{5}$ Termo utilizado nos versos de Manoel de Barros (2010).

${ }^{6}$ Termo de análise de pesquisa que utilizei na Tese de Doutoramento (ROHDEN, 2019).

${ }^{7}$ História menor, aqui inspirada na terminologia empregada por Deleuze e Guattari em Kafka: Por Uma Literatura menor (1996), qual pressupõe uma dimensão baseada na noção de "desterritorialização".
} 
Remexo com um pedacinho de arame nas minhas memórias fósseis.

Tem por lá um menino a brincar no terreiro: entre conchas, osso de arara, pedaços de pote, sabugos, asas de caçarolas etc.

E tem um carrinho de bruços no meio do terreiro.

[...] O menino é hoje um homem douto que trata com física quântica.

Mas tem nostalgia das latas.

Tem saudades de puxar por um barbante sujo, umas latas tristes.

(BARROS, 2010, p. 367)

Contudo, remexer as memórias fosseis da infância se constitui numa possibilidade de sentir a história pulsar no presente, ser sensível ao tempo que não é exterior a nós, mas que se faz em nós próprios, ligado a tudo e a todos (MERLEAU-PONTY, 1994). Tudo isso faz com que nos reconheçamos não apenas parte, mas a própria pesquisa, as próprias interpretações e nisso, "interpretar o mundo não é conhecê-lo, mas criá-lo. É criando o nosso mundo que nos tornamos cocriadores do mundo, porque sem nós, sem nossa interpretação, esse mundo que é nosso não poderia existir” (DIAS, 2011, p. 16-17). Assim, “[...] não há como estar sobre o mundo, como se fosse possível estar fora dele para se sobrepor a ele. Estamos sempre imersos na paisagem. Nós somos o próprio mundo” (RESENDE DUARTE, 2019, p. 118).

Destarte, este texto é um convite para criar mundos, mundos de memórias, mundos de infâncias, mundos para sentir, para imaginar, para brincar com as memórias crianceiras, para educar um olhar de pássaro, construir um olhar azul, um mundo infante, bricoleur, para viver a pesquisa, pois, fenomenologicamente, isso dá sentido à vida, dá sentido à essa escritura, à travessia pesquisada.

Assim, é desta forma que ensejo a poiesis desta escritura, sem as tradicionais pretensões científicas de apontar sínteses ou quaisquer soluções, tampouco elencá-la em uma área de conhecimento isolada, mesmo porque a experiência da pesquisa, a experiência do vivido, me escapa a entendimentos fixos e acabados. A sensação é de fluxo que encontra potências nas memórias ‘móveis’ e ‘fósseis' de infâncias. Um convite para deslocar o olhar de um tempo presente, que toca o passado, para pensar a infância, o brincar, a partir das ressonâncias de vozes que querem ser ouvidas: vozes que ressoam memórias que transitam em diferentes temporalidades num mesmo tempo.

O ensejo aqui é de uma pesquisa menor, que se faz num processo de inacabamento, que se faz criação, que se faz múltipla e singular numa oscilação entre desterritorialização e reterritorialização (DELEUZE; GUATARRI, 1996) incessante, contornadas pela estética do visível e do invisível (MERLEAU-PONTY, 1999). Penso que este relato que me proponho a fazer se distancia de apresentar 'resultados de pesquisa' como fixos e finalizados. Particularmente, entendo que fenomenologicamente esteja voltado para apresentar os encontros e desencontros de corpos, entre os cacos das memórias permeados pelos relances dos esquecimentos, ou ainda, entrelaces de memórias: eu-outro-mundo, marcados pela estética criativa de vida e de morte que um texto traz em seu íntimo quando se oferece aos seus leitores.

\section{O BRINCAR ENQUANTO PRODUÇ̃̃O CULTURAL DA INFÂNCIA: “VOCÊ BRINCAVA COM O QUE TINHA, SE VOCÊ NÃO TINHA, VOCÊ INVENTAVA!'8}

Isto porque a gente foi criado em lugar onde não tinha brinquedo fabricado. Isto porque a
gente havia de inventar os nossos brinquedos: eram boizinhos de osso, bolas de meia, auto-
móveis de lata. Também a gente fazia de conta que sapo era boi de cela e viajava de sapo Manoel de Barros, 2010.

Restos. Sobras. Latas. Cordas. Gravetos. Pedrinhas. Pedaços: de pau, de ferro, de pano. Trapos. Elásticos. Fios. Barbantes. Madeira. Barro. Penas. Espigas. Pó-de-serra. Retalhos. Sucatas. Estes e outros tantos outros elementos configuravam o brincar do cotidiano dos meninos e meninas do/no m/Mato, no lócus e na temporalidade investigada. Qualquer sobra, qualquer resto de alguma coisa se tornava um brinquedo. Com pedacinhos de madeira se construía "grandes cidades" (MIGRANTE 3, 2012). Com

\footnotetext{
${ }^{8}$ Depoimento Migrante 2, 2016.
} 


\section{A CULTURA DO BRINCAR E A PRESENÇA DA MIMESE, DO DESVIO E DA REPETIÇÃO NAS MEMÓRIAS DE INFÂNCIA DE MIGRANTES DE SINOP-MATO GROSSO}

espigas de milho e pedaços de pano se fazia bonecas “com vestidos triunfantes” (MIGRANTE 4, 2017); Com pedacinhos de tijolos e uma placa de alumínio um fogãozinho surgia para "fazer comidinha de verdade” (MIGRANTE 5, 2016).” Com um pedaço de barbante e duas latas amarradas em cada ponta, era possível "telefonar para os amigos" (MIGRANTE 1, 2017). Galhos de árvores se transformavam em "casa da árvore" porque "[...] a gente fazia de conta que tinha uma casinha na árvore, mas não tinha, era só de imaginação” (MIGRANTE 5, 2016). Poças d’água se tornavam grandes rios pois, "para nós crianças eram tão grandes que pareciam rios, hoje eu vejo que nem eram tão enormes assim, mas na cabeça da gente quando criança, as coisas pareciam que era tudo muito maior!” (MIGRANTE 3, 2012).

Estes são alguns dos exemplos das maneiras de brincar, modos de aprender e de experienciar a infância no contexto histórico pesquisado. Nas mãos das crianças da temporalidade em estudo, qualquer coisa artesanalmente se tornava algo, e logo depois se tornava outra coisa: devir-brinquedos. Seus quintais eram maiores que o mundo, "num espaço onde as ações se desdobravam, onde criação e invenção eram nomes próprios, vistos pela ótica das artes de fazer” (ROHDEN, 2016, p. 84), tudo se criava, se improvisava - bricoleurs infantes, saltitantes, peraltas. Bricolagens de uma arte de 'infancionar' no chão, nos rios, na floresta: "Eu lembro que a gente gostava de pegar restos de fios das construções para brincar de fazer artesanatos" (MIGRANTE 3, 2016). "A gente pegava a lama e brincava de moldar artesanato" (MIGRANTE 4, 2016).

Assim, no universo do brincar, em especial no mundo da criança que brincava, no contexto historicamente em investigação, se aproximavam e misturavam-se os mais diferentes artefatos: madeira, latas, pedrinhas, papel, tecidos, elásticos, plásticos, vidro, madeira, pó de cerra, metais, areia, osso, barro, gravetos. Estes materiais eram "mimetizados e transformados em brinquedos numa relação de entrega, emancipação, contemplação e supremacia em relação ao objeto, resistência à banalização, criação e repetição” (ALVES; SILVA et al., 2011, p. 50). Descrevo então, alguns depoimentos que selecionei, os quais associo à discussão proposta:

[...] eu tinha que inventar meus brinquedos. Eu pegava coisas velhas ou restos de coisas que sobravam por exemplo, caixinhas, potes de plástico, e eu cortava e modelava meus brinquedos. Então, eu construía navio, carrinhos, eu lembro que com uma garrafa de amaciante eu fiz a Kombi do Scubby Doo'. Então eu criava meus brinquedos, e eu brincava muito, eu gostava de brincar de misturar as cores de anilina eu as fazia cair no mesmo lugar e as cores se misturavam (MIGRANTE 2, 2016).

FIGURA 2: CRIANCSAS BRINCANDO COM RESTOS DE MADEIRA E DE OUTROS RESÍDUOS, 1981.

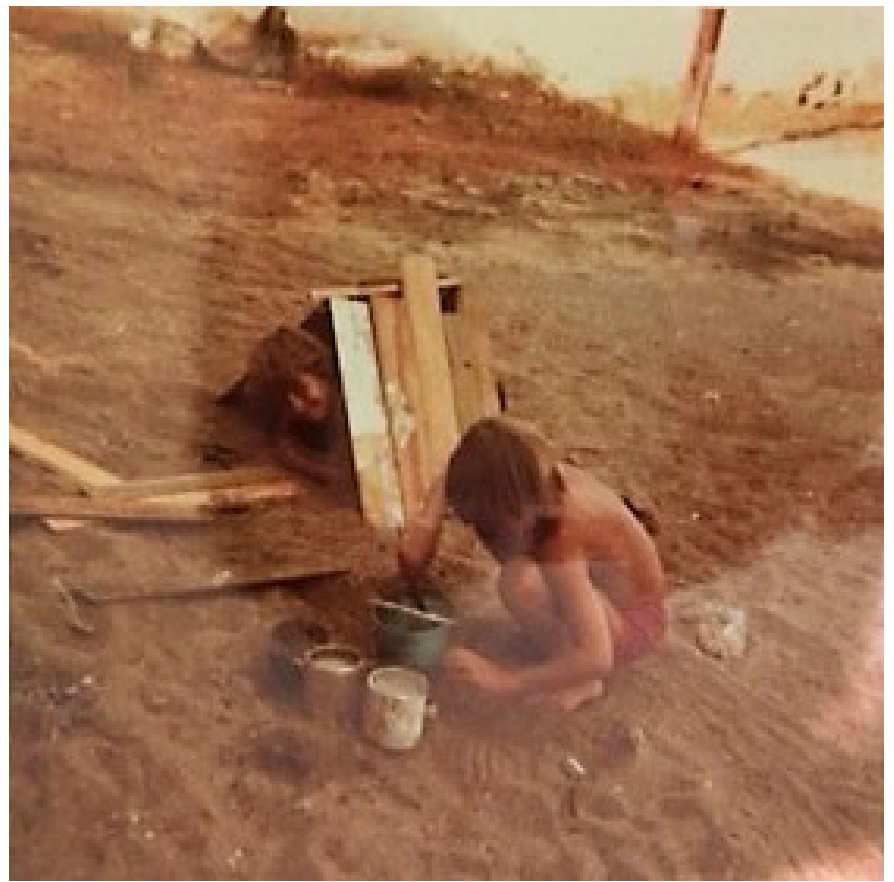

FONTE: MIGRANTE2, ACERVO PESSOAL, 1981

\footnotetext{
${ }^{9}$ Trata-se de um desenho animado estadunidense produzido pela Hanna-Barbera e criado no ano de 1969 por Iwao Takamoto.
} 
Eu adorava pular tábua: quanto mais alto, melhor [...], tinha as tábuas especiais para pular e os toquinhos que achávamos nas serrarias, eram restos, mas para a criançada era um tesouro! (MIGRANTE 3, 2011).

A gente construía brinquedos, fazia bola de meia para arremessar no palhaço, era a criatividade mesmo! Usávamos latas de azeite para jogar bets ${ }^{10}$, fazíamos de restos de madeira os tacos. Reunia todas as crianças da rua para jogar bets a tarde toda. Era tudo nós que construíamos, que organizávamos os pares, as regras. Não precisava de adulto, a gente se ajeitava sozinhos (MIGRANTE 6, 2011).

Naquele momento não existia televisão, ou internet, ou qualquer brinquedo destes de hoje, era só inventar mesmo. A gente catava nos lixos latas fazia furos nelas, amarrava uma lata na outra, pegava uns pedaços de madeira e montava uns tratores e saía puxando, a diversão estava mais em montar do que em ficar puxando depois. Porque a gente ficava dias catando os restos de latas, madeiras, potes, na vizinhança e depois fazia todo um projeto de montar tratorzinhos com eles (MIGRANTE 4, 2017).

Contextualizando os testemunhos orais com os escritos de Benjamin (2002) e a poesia de Manoel de Barros, pode-se inferir que tanto nos pressupostos teóricos do filósofo quanto nas memórias dos sujeitos pesquisados, ou na poética de Barros, as brincadeiras aparecem como uma forma em que a criança explora o mundo, atribuindo significados próprios. Os brinquedos surgiam como espelhos da autonomia daquelas crianças. É na terra que estavam os “mais incomparáveis objetos de atenção e da ação das crianças” (BENJAMIN, 2002, p. 103) e, portanto, as crianças criavam, imaginam, inventam, formulavam, faziam, refaziam, construíam, reconstruíam. "É assim que as crianças formam seu próprio mundo das coisas, com um pequeno universo inserido em um maior: imitam e criam, fazem de novo, com novos arranjos e interpretações, a partir daquilo que têm de modelo" (ALVES; SILVA et al. 2011, p. 54).

Assim sendo, nesse próprio mundo das coisas, criado e recriado pelas crianças, é que concebemos a cultura do brincar como também parte da produção cultural da infância. E, por "culturas da infância" entende-se, com Sarmento (2003, p. 3-4), “a capacidade das crianças em construírem de forma sistematizada modos de significação do mundo e de ação intencional, que são distintos dos modos adultos de significação e ação". Ainda, é relevante compreender de acordo com o autor que "as culturas da infância transportam as marcas dos tempos, exprimem a sociedade nas suas contradições, nos seus estratos e na sua complexidade" (SARMENTO, 2003, p. 4).

De tal modo, no espaço de produção cultural da infância investigada, destacando nosso olhar para a cultura do brincar, entendemos com Brougère (2008, p. 89) que "é necessário convir que em relação à brincadeira, estamos longe de nos situar num campo de certezas”. E neste cenário, a intenção que infere nesta pesquisa não é de ficar justificando a valoração ou não da brincadeira, na tentativa de persuasão do leitor, ou mesmo de seguir a tendência de "fazer da brincadeira a panaceia do desenvolvimento" (BROUGÈRE, 2008, p. 95), pois como nos diz Brougère (2008, p. 89), “a brincadeira é boa porque a natureza pura representada pela criança é boa”. Ainda, se faz relevante mencionar que a brincadeira não é uma ação inata do homem, ela pressupõe uma aprendizagem social, ou seja, aprende-se a brincar (BROUGÈRE, 2008).

A inserção da criança no brincar é iniciado a priori pelas pessoas que cuidam dela, em especial, no primeiro momento, pela sua mãe. Como demonstram os estudos do autor supracitado, na inserção progressiva no brincar iniciada junto a mãe, a criança "aprende a compreender, dominar e depois produzir uma situação específica, distinta de outras situações” (BROUGÈRE, 2008, p. 98).

Para Maturana e Verden-Zõller (2004, p. 232), numa sociedade matricial ${ }^{11}$, à criança amplia a autoconsciência e a consciência social quando vive desde o início "a relação com sua mãe na intimidade da completa aceitação e confiança de seu encontro corporal com ela no brincar". Deste modo, a este ato de ampliar nosso domínio cognitivo reflexivo que sempre implica uma experiência é que podemos chegar a ver o outro como igual, ato este que os autores se referem ao amor. Assim, “[...] tudo o que nos permite perceber que o amor ou [...] a aceitação do outro junto a nós na convivência, é o fundamento biológico

\footnotetext{
${ }^{10}$ Bets ou Jogo de Tacos é um esporte que descende do “cricket” britânico.

${ }^{11}$ Segundo Maturana e Verden-Zõller (2004) a cultura matricial era a característica da organização de nossos ancestrais que viviam uma dimensão Poiética com tudo e com todos.
} 


\title{
A CULTURA DO BRINCAR E A PRESENÇA DA MIMESE, DO DESVIO E DA REPETIÇÃO NAS MEMÓRIAS DE INFÂNCIA DE MIGRANTES DE SINOP-MATO GROSSO
}

do fenômeno social. Sem amor, sem aceitação do outro junto a nós, não há socialização, e sem esta não há humanidade” (MATURANA; VARELA, 2004, p. 269).

Neste sentido, pode-se compreender com Maturana e Verden-Zõller (2004), que a experiência do brincar está infundida com a experiência do amar, do emocionar, do "linguajar" de doar-se em relação de cumplicidade à natureza, ao outro. Elementos estes, que os autores consideram essencialmente como fundamentos esquecidos do humano, sentidos estes que se fazem na experiência da convivência humana pela linguagem, "todo conhecer humano [...] é sempre vivido numa tradição cultural" (MATURANA; VARELA, 2004, p. 265). Deste modo, "só temos o mundo que criamos com o outro" (MATURANA; VARELA, 2004, p. 268).

Diante disso, a brincadeira pressupõe uma comunicação, uma expressão, uma fala, um gesto e ela acontece fundamentalmente num espaço social. Como sugere Brougère (2008), para que uma brincadeira aconteça, é necessário uma comunicação específica entre os pares, uma 'metacomunicação', cujos conteúdos mostram que se trata de uma ação do brincar. Segundo o autor, "o simples gesto de estender um brinquedo pode servir de metacomunicação suficiente e deflagar a brincadeira, espaço específico onde as atividades vão ter um outro valor” (BROUGÈRE, 2008, p. 99). Deste modo, o ato de brincar supõe uma comunicação e uma interpretação pelo sujeito que brinca e neste cenário, "a brincadeira é uma mutação de sentido, da realidade: as coisas aí se tornam outras” (BROUGÈRE, 2008, p. 99).

Nas brincadeiras as coisas se transformam, um mundo de significados próprios se forma, oferecendo-nos pressupostos para nos auxiliar a perceber a criança ao longo da história como produtora de cultura, de conhecimentos, de sentidos. Neste âmbito, conceber a criança em conexão com o mundo e o que está a sua volta, possibilita o entendimento de que ela "debita ao mundo seus sonhos assim como suas percepções” (MERLEAU-PONTY, 1999, p. 464), pois ela “acredita que o sonho se passa no quarto, ao pé de sua cama, e só é visível para aqueles que dormem” (MERLEAU-PONTY, 1999, idem.). Neste primeiro momento, "o mundo é ainda o lugar vago de todas as experiências" (MERLEAU-PONTY, 1999, p.465). Experiências estas que se fazem "ao relacionar-se com o mundo, com as coisas guiadas pela percepção" (DIAS, 2006, p. 968) e deste modo, "a criança experimenta, também, a inerência de sua consciência ao seu corpo e ao de outra consciência perceptiva, como um ser no mundo” (DIAS, 2006, p. 968).

\section{A MIMÉTICA, A ARTE DO DESVIO E DA REPETICÃA NAS BRINCADEIRAS DE INFÂNCIA NAS MEMÓRIAS DE MIGRANTES DE SINOP-MT}

\author{
Você não é de bugre? - ele continuou. \\ Que sim, eu respondi.
}

Veja que bugre só pega por desvios, não anda em estradas Pois é nos desvios que encontra as melhores surpresas e os ariticuns maduros. Manoel de Barros, 2010.

Repetir, repetir - até ficar diferente. Repetir é um dom do estilo. Manoel de Barros, 2010.

Quisera uma linguagem que obedecesse a desordem das falas infantis do que as ordens gramaticais. Desfazer o normal há de ser uma norma.

Manoel de Barros, 2010.

As epígrafes dessa sessão são intencionais no sentido de pensar a cultura do brincar a partir da capacidade mimética, da arte dos desvios, da repetição que as memórias de infância nos trazem nas narrativas construídas e deste modo, contribuem para pensarmos sobre as culturas da infância. Era nos desvios que a criança 'encontrava as melhores surpresas', era 'repetindo' inúmeras vezes a mesma brincadeira que ela sempre fazia acontecer algo diferente, era na 'imitação' que se recriava ações dos adultos pela desordem das falas infantis, e assim nunca se fazia algo igual ao do mundo adulto, pois, na imitação elas inventavam seus próprios mundos, 'desfazendo a norma', isso era/é norma.

Contudo, a cultura infantil em análise neste estudo, destaca que mesmo diante da ordem, da disciplina da época, da imposição de valores e normas, havia movimentos que desconfiguravam a ordem 
dominante, entendida por Certeau como as táticas que moviam os sujeitos nas suas artes de fazer, imprecisas, sem localização exata, surgidas das contingências da situação, de modo a aproveitar as lacunas do lugar da ordem, fruto da "[...] inteligibilidade criada no aqui e agora, exigindo inteligência viva, parecendo desprezar modelos preestabelecidos, estando constantemente apreendendo a situação e agindo sobre ela improvisando saídas” (AZEVEDO; ARAÚJO, 2011, p. 481). Nesse âmbito, Azevedo e Araújo (2011, p. 481), fazem uma ressalva de que:

O ser humano comum é capaz de inventar táticas buscando escapar das teias da conformação, mesmo enredados no poder do inconsciente - como um "lugar" em nós mesmos que não temos domínio - e no poder das ideologias dominantes - que nos forçam a pensar como pensamos e agir como agimos - os seres humanos ordinários são capazes de criar e recriar maneiras de viver sonhos e realidades indo além da submissão pela via da arte do fazer.

Tantas são as artes de fazer (CERTEAU, 1998), que até mesmo as práticas, os rituais que a escola efetivava cotidianamente como: formar filas antes de entrar para sala, cantar hinos, silenciar qualquer 'barulho' não permitido, serviam para que as crianças mimeticamente brincassem e recriassem tais práticas, dando a elas o seu próprio significado. Como nas recordações abaixo:

[...] também brincávamos de escolinha, tínhamos uma lousa pequenininha, minha irmã era professora, eu era aluna e tinha mais um monte de aluna invisível (risos). Aí minha irmã reproduzia muito bem as professoras, ela dizia: Silêeeencio! Ela imitava as professoras (risos). Uma coisa legal quando nós brincávamos de escolinha: antes de entrar para a sala fictícia nós tínhamos que formar a fila, igual na escola de verdade, formar fila, tomar distância, ficar em posição de sentido, cantar o hino, mas só tinha eu na fila, o resto era tudo invisível (risos) mas a minha irmã ficava gritando: "arruma esta fila, que esta fila está torta," "enquanto não endireitar a fila ninguém entra”, mas só tinha eu na fila! (risos) mas eu ficava lá um tempão... ela fazia igualzinho as irmãs, aí até a fila que só tinha eu precisava ficar reta, depois entrava na sala, limpava a carteira fictícia, colocava a toalhinha em cima da mesa para não sujar nada, tudo em ordem, e a minha irmã reproduzia certinho as professoras, aí minha mãe fazia um lanchinho e chamava; “olha, venham comer o lanche, tá na hora do lanche!!!” Aí [...], corríamos comer, depois voltava para a nossa escolinha. (MIGRANTE 4, 2012).

Diante desta brincadeira mimética, é interessante os apontamentos que Benjamin faz no ensaio "O corcundinha”, a qual integra a obra "Infância berlinense: 1900", na qual o autor utiliza a personagem do Corcunda simbolicamente para relacionar as ações que aproximam e que ao mesmo tempo se distanciam de si mesmo, características que surgem quando a criança brinca mimeticamente, como sendo um jogo da infância, que deve ser concebida como possibilidade da criança afirmar-se enquanto sujeitos.

Neste sentido, pode-se considerar próprio da ação mimética “a necessidade do esvaziar-se parcial e momentaneamente de si para que a outra substância possa fazer parte de quem realiza o exercício da mimese” (SANCHES, 2017, p. 10). Ou seja, a presença do mimetismo no brincar infantil, necessita que a criança se distancie de si para se tornar, como nas memórias da Migrante 3, a professora, a diretora da escola, que exige silêncio, fila reta, e tantas outras ações que eram produzidas para o disciplinamento das crianças, mas que ao brincar mimeticamente elas, Migrante 3 e sua irmã, recriavam tais ações, resignificando-as. Deste modo, tal brincadeira de 'reproduzir' as práticas da escola, não eram produzidas apenas como mera imitação do mundo adulto, mas como meios de criação, invenção e, desta forma produziam cultura, uma vez que toda brincadeira mimética é um processo criativo de reprodução interpretativa e não meramente uma questão de simples imitação (CORSARO, 2012).

Corsaro (2012), nos auxilia a compreender que as crianças constroem entre si e com os adultos, o papel efetivo social da criança. Quando na participação na sociedade a criança, ao mesmo tempo em que é afetada também produz efeitos na sociedade, ou seja, a criança não apenas imita ou reproduz algo, mas cria, recria, reinventa atribuindo novos significados às ações que lhe são apresentadas, no contexto social que estão inseridas. Nas palavras de Corsaro (1992, p. 29, tradução minha): "as crianças não se limitam a internalizar a sociedade e a cultura, mas contribuem ativamente para a produção e mudança culturais".

Diante do exposto, acrescenta-se com Benjamin (2002) que as crianças não constituem nenhuma comunidade isolada, mas antes fazem parte da comunidade a qual pertencem, da mesma forma que seus 


\section{A CULTURA DO BRINCAR E A PRESENÇA DA MIMESE, DO DESVIO E DA REPETIÇÃO NAS MEMÓRIAS DE INFÂNCIA DE MIGRANTES DE SINOP-MATO GROSSO}

brinquedos testemunham uma vida autônoma que se faz em um mundo de diálogo de sinais entre a criança e as pessoas que convivem com ela. O brincar se constitui, desta forma, como uma cultura específica produzida pela criança e seus pares, uma vez que estas interpretam de modo criativo, aos seus modos, a cultura dos adultos, reinventando-a, atribuindo outros e novos significados e que portanto, não deve ser considerada como uma mera imitação (BENJAMIN, 2002).

Na narrativa da Migrante 3 (2016), entre suas brincadeiras narradas, ela traz uma recordação, que demonstra a capacidade inventiva de brincar com os restos que encontrava, uma vez que eram os materiais que dispunham para brincar, porém, tal brincadeira era um modo criativo, transformador de ‘aparentemente' imitar a vida adulta:

[...] a gente brincava muito de casinha, de fazer comidinha de verdade. A gente pegava tijolo ou alguma coisa de apoio, pegava algum pedaço de Eternit ${ }^{12}$ para a tampa e fazia fogueirinha embaixo, aí fazíamos comidinha de verdade, eu tinha umas panelinhas que pareciam de verdade que foi trazido do Paraná, e a gente fazia comidinha de verdade e comíamos, era uma delícia.

Em outro depoimento, encontro mais modos da capacidade mimética (BENJAMIN, 2002) das crianças do passado:

Lembro que eu, meus irmãos, meus primos, tínhamos que trabalhar na terra para ajudar os pais. Ai a gente fazia que ao roçar, nós estávamos brincando, porque a gente imitava nosso pai, nossos tios. A gente falava que ia trabalhar para comprar um trator, uma casa maior, mas era tudo de brincadeira, porque a gente fazia de conta que era os nossos pais, a gente até engrossava a voz (MIGRANTE 6, 2017).

Nestes exemplos de memórias do brincar de modo a imitar a vida adulta, faz-se necessário enfatizar que "a brincadeira é antes de tudo, uma confrontação com a cultura” (BROUGÈRE, 2008, p. 76). Deste modo, "na brincadeira, a criança se relaciona com os conteúdos culturais que ela reproduz e transforma, dos quais ela se apropria e lhes dá uma significação” (BROUGÈRE, 2008, p. 77). Neste sentido, é importante salientar que toda brincadeira, por mais que aos olhos de quem contempla se apresenta meramente como uma imitação adulta, da cultura qual a criança está inserida, para quem brinca é uma apropriação de tal cultura, a brincadeira passa por um universo de sentidos para a criança, qual dá sempre um novo e outro significado para a ação do brincar. Os migrantes 3 e 6 não reproduziam meramente ações da vida adulta, da cultura que estavam inseridos, mas, apropriavam-se dela, transformavam-na aos modos da criança em tal espaço e tempo histórico, criavam e recriavam, de modo a produzir novos significados para as brincadeiras, constituindo-se como sujeitos históricos, sociais, culturais.

Benjamin contribui para estes apontamentos, quando nos proporciona a reflexão de que:

As crianças são inclinadas de modo especial a buscarem todo e qualquer local de trabalho onde visualmente transcorre a atividade sobre as coisas. Sentem-se irresistivelmente atraídas pelos resíduos de construções, no trabalho de jardinagem, ou doméstico, na costura ou na marcenaria. Em produtos residuais reconhecem o rosto que o mundo das coisas volta exatamente para elas, e para elas unicamente. Neles, elas menos imitam as obras dos adultos do que põem materiais de espécie muito diferentes, através daquilo que com elas aprontam no brinquedo, em uma nova, brusca relação entre si. Com isso as crianças formam para si seu mundo de coisas, [...] (BENJAMIN, 1987, p. 16, grifos meus).

Diante do exposto, Gagnebin (1993, p. 80), nos orienta diante das inferências de Benjamin, dizendo que o filósofo nesta discussão, “distingue dois momentos principais da atividade mimética especialmente humana: não apenas reconhecer, mas produzir semelhanças. Essa produção mimética caracteriza a maior parte dos jogos, das brincadeiras infantis”.

Contudo, a ação mimética em tal contexto histórico estudado, permitia que a criança manipulasse elementos construindo um aprendizado próprio, de um modo que também lhe era próprio, atribuindo sons (como por exemplo engrossar a voz no caso do Migrante 6 citado anteriormente), construindo valores

\footnotetext{
${ }^{12}$ Marca de um tipo de telha ondulada, feita de fibrocimento, utilizada para cobertura de casas, etc.
} 
e juízos, habilidades, desejos. "A criança quer puxar alguma coisa e tornar-se cavalo, quer brincar com areia e tornar-se padeiro, quer esconder-se e torna-se bandido ou guarda” (BENJAMIN, 2002, p. 93). Era isto que a criança da época fazia e queria fazer e neste ponto, "não há dúvidas que brincar significa sempre libertação. Rodeadas por um mundo de gigantes, as crianças criam para si, brincando, o pequeno mundo próprio” (BENJAMIN, 2002, p. 85).

Neste cenário, os Migrantes 3, 6 e seus amigos e amigas, não brincavam somente de atividades consideradas humanas, uma vez que a imitação não se restringe à representação fixa e pontual de um adulto. Ao contrário, "a atividade mimética sempre é uma mediação simbólica, ela nunca se reduz a uma imitação” (GAGNEBIN, 1993, p. 80). Neste contexto, ainda é possível ouvir a voz da Migrante 5 (2017) quando relata "eu ficava em cima das árvores por horas escutando os passarinhos, eu brincava que eu era um bem-te-vi, pra mim até hoje é o canto mais lindo”. Assim, na ação mimética do brincar, a criança no passado, no presente assim como a criança dos versos de Manoel de Barros brinca que é pedra, que é boi, que é ave, que é dinossauro, que é princesa ou bruxa, que é peixe, que é um lindo bem-te-vi, cuja sonoridade do canto adentra por um instante este texto, 'desfazendo mais uma vez a norma' (BARROS, 2010) bem-te-vi, bem-te-vi, bem-te-vi...

\author{
O leve e macio \\ raio de sol \\ se põe no rio. \\ faz arrebol... \\ Da árvore evola \\ amarelo, do alto \\ bem-te-vi-cartola \\ e, de um salto \\ Pousa envergado
no bebedouro
a banhar seu louro \\ pelo enramado... \\ de arrepio, na cerca \\ Já se abriu, e seca.
}

(MANOEL DE BARROS, 2010, p. 107)

Contudo, “a brincadeira dá testemunho da abertura e da invenção do possível, do qual ela é o espaço potencial do surgimento" (BROUGÈRE, 2008, p. 106). Neste sentido, o brincar constitui propriamente o espaço para a criatividade, a curiosidade, a invenção. Pelo brincar a criança comunga de um território de possibilidades, de fluxos, de potências. Ela comunga da presença do outro, elabora relações com o meio, percebe o mundo e se projeta a ele; a criança ao brincar faz 'comunhão com as coisas' (BARROS, 2010). Comunhão esta que indica, de acordo com Merleau-Ponty (1999), os modos do corpo de se apropriar do mundo, e consequentemente, transformá-lo em mundo humano.

Neste cenário, há também que se assinalar as características dos desvios que pulsam no brincar entre aquilo que se tem entre o sagrado e o profano, "brincando, o homem desprende-se do tempo sagrado e o esquece no tempo” (AGAMBEN, 2005, p. 85). Nas narrativas construídas, as memórias nos trazem analogias a esta afirmação de Agamben, "a gente perdia a noção do tempo, a gente acordava na rua e dormia na rua, de tanto que a gente brincava!” (MIGRANTE 5, 2017).

Benjamin (1987), ao relatar suas memórias de infância, apresenta a relação que a criança elabora entre o 'sagrado' que exercia um poder e o 'profano' aquilo que desativava tais dispositivos controladores, oferecendo-se à criança como algo que ela podia transformar em objeto de suas vontades, de seus desejos. 


\section{A CULTURA DO BRINCARE A PRESENÇA DA MIMESE, DO DESVIO E DA REPETIÇÃO NAS MEMÓRIAS DE INFÂNCIA DE MIGRANTES DE SINOP-MATO GROSSO}

Para Agamben (2005, p. 71), "profanar significa restituir ao uso comum o que havia sido separado na esfera do sagrado". No entanto, "não significa simplesmente abolir e cancelar as separações, mas fazer delas um uso novo, a brincar com elas" (AGAMBEN, 2005, p. 75). "Imagina se as irmãs ${ }^{13}$ pegassem a gente lendo gibis? Mas, a gente trocava muito gibi na escola embora fosse proibido" (MIGRANTE 7, 2012). Deste modo, o gibi levado para o ambiente ‘sagrado' da escola também se fazia um modo de brincadeira, de troca de coleções, algo que as crianças gostavam de fazer, mas que entretanto, eram impedidas de levar, de ler, de fazer suas trocas, uma vez que "os gibis desvirtuavam da Língua Portuguesa, ou ensinavam fazer peraltices na cabeça das Irmãs” (MIGRANTE 7, 2012). Contudo, as crianças atribuíam outro uso a eles, de troca, de brincadeira, mesmo que escondidas, o “desvio" apontava para um jogo, para uma experiência lúdica (BENJAMIN, 1987). Para Benjamin o desvio de uma prática pré-determinada demonstra como a relação entre a adaptação de uma realidade e a autonomia podem auxiliar para constituir o ser humano no âmbito da experiência da modernidade (GAGNEBIN, 2005).

Tais desvios do brincar, em especial no espaço da escola, configuravam um território onde as crianças subvertiam a ordem do 'não poder' do 'não dever'. Havia um jogo como pontua Certeau (1998) entre o 'fraco' e o forte', um jogo onde as crianças encontravam a partir de táticas 'mil maneiras' para brincar, driblando as estratégias do lugar (CERTEAU, 1998), do poder.

Outra característica presente no brincar das memórias de infância pesquisadas, é a repetição, que "proporciona à criança uma temporalidade que a permite incorporar a experiência numa autonomia progressiva” (SANCHES, 2017, p. 8). De acordo com Benjamin (2002, p. 102), "a essência do brincar não é um "fazer como se”, mas um "fazer sempre de novo", transformação da experiência comovente em hábito. O autor convida-nos a pensar que para a criança, acima de todas as regras e ritmos particulares do jogo, da brincadeira, rege a totalidade da 'Lei da Repetição', que nas palavras do filósofo:

Sabemos que para a criança ela é a alma do jogo; que nada a torna mais feliz do que o "mais uma vez”. A obscura compulsão por repetição não é aqui no jogo menos poderosa, menos manhosa do que o impulso sexual no amor. E não foi por acaso que Freud acreditou ter descoberto um “além do princípio do prazer” nesta compulsão. E, de fato, toda e qualquer experiência mais profunda deseja insaciavelmente, até o final de todas as coisas, repetição e retorno, restabelecimento da situação primordial da qual ela tomou o impulso inicial (BENJAMIN, 2002, p. 101).

Deste modo, é a lei do 'mais uma vez' que convida a criança ao desejo de brincar novamente da mesma brincadeira, no entanto, exprimindo a cada nova vez um significado diferente, como um "saborear, sempre de novo e de maneira mais intensa, os triunfos e as vitórias” (BENJAMIN, 2002, p. 101). Para o autor, o repetir provoca o hábito como o vestir, o lavar-se, comer, dormir, que devem ser inseridos na vida da criança de forma lúdica, pois segundo o filósofo o "hábito entra na vida como brincadeira, e nele, mesmo em suas formas mais enrijecidas, sobrevive até o final um restinho da brincadeira - "Repetir, repetir - até ficar diferente, repetir é um dom do estilo” (BARROS, 2010, p. 300). Neste sentido, brincar é não apenas um "fazer de conta", mas essencialmente, um "fazer de novo", de "transformar a experiência mais comovente em hábito” (BENJAMIN, 2002, p. 101). Vejamos os depoimentos:

Todos os dias a gente saia da escola e ia num lugar onde tinha uns morrinhos com muita mata e cipós, a gente se pendurava naqueles cipós e ia... para nós era balanço, cada um tinha um cipó, e eu sempre era muito danada e me estrepava. A gente corria muito, não parava, parecia que tinha trocado as pilhas [...]. A gente atravessava um matinho para chegar até em casa e não tinha jeito era achar um cipó a gente ia embalado no cipó, era muito bom atravessar aquela mata e se pendurar nos cipós, não era uma vez ou outra, a gente perdia a conta de quantas vezes fazia isto. (MIGRANTE 5, 2017).

A gente tinha um vizinho que tinha um cachorro [...]. E a gente ia muito à casa deste vizinho porque lá a gente brincava de casinha, um era o papai, tinha a mamãe, os filhinhos, a gente reproduzia as ações dos adultos, fazia almoço, tinha a cozinha, tudo improvisado. Mas, o que mais me marcou foi que no final toda a vez a gente sempre brincava de fugir do cachorro. O menino segurava o cachorro, a gente corria dele e subia em alguma coisa e tinha que

\footnotetext{
${ }^{13}$ Em referência às Irmãs Católicas da Congregação Santo Nome de Maria, que vieram para direcionar todos os trabalhos educacionais e sociais da Gleba Celeste no período da colonização.
} 
ficar lá porque daí ele soltava o cachorro que ficava latindo pra gente descer, a gente ficava horas lá rindo do cachorro tentando pegar a gente. Provavelmente o cachorro era bonzinho, nem mordia, mas na cabeça da gente ele era um monstro que queria pegar a gente (risos) (MIGRANTE 2, 2016).

De acordo com Santos (2015, p. 130), “a diferença entre a repetição e a criação no jogo está nos limites entre conhecer o mundo e recriá-lo à maneira do sujeito que o experimenta, pois, a criação revela uma atitude positiva de resposta frente ao mundo”. Diante disto, é possível perceber nas narrativas que tal repetição dos jogos, das brincadeiras, da manipulação dos mesmos brinquedos, enfim, que tais ações não se davam da mesma maneira, como uma forma reprodutiva de brincar, mas, de manifestar ações muitas vezes pela mimese do mundo adulto, mas de forma sempre diferente, criativa, onde a criança era cercada por experimentações de 'um fazer de novo' em uma dimensão na "relação de compreensão do mundo e do sentido de uma experiência vivida” (SANTOS, 2015, p. 130).

\section{CONSIDERAÇ̃̃ES FINAIS}

Lembrar da infância tem cheiro, sabor, sons, paisagens, texturas. Lembrar da infância é sentir o passado que caminha com o presente, de mãos dadas, como se 'o mundo começasse de novo ali' (BARROS, 2010), no mesmo lugar, na repetição de uma brincadeira que não cessa de querer 'fazer outra vez', pois, "eu não via a hora de chegar o outro dia para brincar de novo" (MIGRANTE 6, 2012). "E tinha um canto até para brincar de novo que era bem assim: quem quer brincar coloca o dedo aqui, que já vai fechar o abacaxi” (MIGRANTE 4, 2017).

Diante disto, “toda nossa infância está por ser reimaginada” (BACHELARD, 2009, p. 94), seja pelas nossas próprias recriações das memórias dela, seja pelas vozes das nossas famílias que recontam, reimaginando nossas histórias de infância. E ao reimaginar nossa infância, temos a possibilidade de reencontrá-la na própria vida dos nossos devaneios de criança [...] (BACHELARD, 2009, p. 94). Deste modo, "o devaneio voltado para a infância nos restitui à beleza das imagens primeiras" (BACHELARD, 2009, p. 97), nas quais conseguimos achar ali, na nossa intimidade crianceira, o começo de tudo: dos meninos e meninas que fomos, quando então, nos vemos outra vez de "joelho ralado, machucados de tanto brincar" (MIGRANTE 5, 2016).

Contudo, esse texto foi um ensaio que pretendeu dizer da criança enquanto coautora de sua própria história, enquanto produtora de cultura, de atores e atrizes sociais seja no passado, seja no presente. Crianças que quando brincavam, quando inventam brinquedos ou brincadeiras aprendiam com o outro, se colocavam no mundo e construíam outros mundos inventados, de faz-de-conta, de imitação (que recria as ações adultas, aos seus modos), de repetição, de "desfazer a norma”. Crianças que sob a ótica da vigilância, driblavam a partir de suas táticas, jogando com as estratégias de um lugar de poder (CERTEAU, 1998) e assim manifestavam as artes dos desvios. As crianças que viviam em meio à floresta brincavam, viviam no âmago do seu ser o profano e o sagrado do tempo de brincar, pois, todo o tempo era tempo de brincar, afinal, "a gente brincava até dormindo, até sonhando" (MIGRANTE 5, 2016). E nesse "mundo do sonho não se voa porque se tem asas, mas acredita-se ter asas porque se voa. As asas são consequências. O princípio do voo onírico é mais profundo. É esse princípio que a imaginação aérea dinâmica deve reencontrar" (BACHELARD, 2001, p. 28).

Deste modo, espero que esse trabalho contribua com novos e outros estudos sobre a infância, sobre o brincar, tanto numa vertente histórica, como também na atualidade, nos estudos voltados para a Educação Infantil, para as discussões sobre o relevante exercício do brincar enquanto produção cultural da infância, com as reflexões sobre a contribuição do brincar com os restos, com as sobras, do criar brinquedos, do contato com a terra, com a natureza que nossas crianças precisam ter para um saudável desenvolvimento integral e para relação íntima com a natureza, com o outro, com o mundo.

Por fim, este foi um texto de uma cultura do brincar do passado, recriado quando as memórias tocam no presente, tempos que caminham juntos e que acenam para o futuro. Neste âmbito, foi um texto de narração, de transcriação do dizer do outro. E, é difícil dizer das memórias que não são as nossas, 


\section{A CULTURA DO BRINCAR E A PRESENÇA DA MIMESE, DO DESVIO E DA REPETIÇÃO NAS MEMÓRIAS DE INFÂNCIA DE MIGRANTES DE SINOP-MATO GROSSO}

mas, que nos encontramos ao meio delas, recriando as nossas. Mundo de cada um, que se faz mundo reinventado junto ao nosso. Percepções singulares, experiência tem nome próprio: o nome de cada um que a viveu. Seria muita ousadia dizer que narrei as memórias dos sujeitos que participaram da travessia de pesquisa. Narrei aquilo que mergulhou em mim e deixo as marcas das minhas próprias experiências quando narro o vivido do outro (BENJAMIN, 1987). Narrar expressa, assim, as experiências vividas, “o narrador retira da experiência o que ele conta: sua própria experiência ou a relatada pelos outros. E incorpora as coisas narradas à experiência de seus ouvintes" (BENJAMIN, 1987, p. 201). No mesmo tempo em que me afeto, sou afetada pelas experiências do outro no confeto (DELEUZE; GUATARRI, 1997).

Com isso, essa narrativa é vida, se faz vida na medida em que a experiência de ouvir, traduz a experiência daquele que conta, de maneira recriada, brotada numa escrita fecundada por um tom lírico e narrativo, nas margens de se fazer uma ciência menor, uma história menor, desterritorializada, habitada por fluxos, ancorada à poesia, na busca da afirmação da vida. Uma narração da percepção, talvez seria o que Merleau-Ponty anunciaria, já que "para que percebamos as coisas é necessário que as vivamos" (MERLEAU-PONTY, 1999, p. 331). Com isso, uma narração implica que a vivamos, de modo a perceber as marcas do doar-se ao ouvir, ao sentir aquilo que vem do outro e aprender com o narrado:

Na narração $[. .$.$] a finitude que nos é própria se doa como limite a partir do qual vida ganha$ forma e se difunde, o que significa que pela narração, que é dizer poético, poiesis, vida recebe, encontra ou reencontra o tempo que lhe sendo próprio a perfaz. Como movimento de apropriação do próprio, narrar é dedicar-se à aprendizagem da vida, é entregar-se à vida como percurso, travessia que só se doa como tempo. (ALBERNAZ, 2009, p. 94).

Finalmente, o ensejo é que esse trabalho afirme a vida a partir do todo narrado, para que seja um texto 'guardador' de memórias do brincar, 'guardador' da infância, assim como Manoel de Barros é um guardador de águas. E então, que ao ler esse trabalho, possamos pensar a criança de hoje, o brincar, a mimese, os desvios, as repetições, trazendo por mais um momento e outra vez, a criança que fomos, que ainda nos habita. E assim, enquanto pesquisadores da infância, professores, educadores, possuir constantemente "no rosto um sonho de ave extraviada" (BARROS, 2010, p. 485) para reaprender a falar "em língua de ave e de criança” (BARROS, 2010, idem), quiçá assim, tudo comece a fazer mais sentido. É preciso viver em estado de infância como nos ensina o poeta desse trabalho, se realmente desejarmos conceber a criança como produtora de cultura, de história, como protagonista de sua própria vida, como autora social, como sujeitos que ao brincar aprendem e ensinam.

\section{REFERÊNCIAS}

AGAMBEN, G. Infância e História: Destruição da experiência e origem da história. Tradução de Henrique Burigo. Belo Horizonte: Editora UFMG, 2005.

ALBERNAZ, A. M. G. L. Vertência do viver no Grande Sertão: Veredas. 2009. (Tese de Doutorado em Ciências da Literatura) - UFRJ: Rio de Janeiro, 2009.

ALVES, C. X.; SILVA, M.; OLIVEIRA, P. R. Memória, Infância e Brincar em Escritos De Walter Benjamin: Cultura Lúdica, Processo De Formação e Prática Docente. Congresso Ibero-americano de Educação. Unesp: São Paulo, 2011. Anais. Disponível em: file://C:/Users/Usuario/Downloads/500012131-1-SM.pdf. Acesso em 07 de set. de 2015.

AZEVEDO, F. A. G.; ARAÚJO, C. M. Meninos dos sinais e a arte de inventar o cotidiano: personagens hostis ou hostilizados na Grande cena da(s) cidade(s). In: $20^{\circ}$ Encontro Nacional da Associação Nacional de Artes Plásticas, 2011. Rio de Janeiro. Anais... Rio de Janeiro: Anpap, 2011. p. 477-489. Disponível em: http://www.anpap.org.br/anais/2011/pdf/ceav/fernando_antonio_goncalvez_de_azevedo.pdf Acesso em 08 de fev. de 2012.

BACHELARD, G. A poética do espaço. Tradução de Antonio de Pádua Danesi. São Paulo: WMF Martins Fontes, 2001. 
BACHELARD, G. A poética do devaneio. Tradução Antonio de Pádua Danesi; revisão da tradução Alain Marcel Mouzat, Mário Lanranjeira. 3ª ed. São Paulo: Editora WMF Martins Fontes, 2009.

BARROS, M. Memórias inventadas: a infância de Manoel de Barros. São Paulo: Editora Planeta do Brasil, 2008.

BARROS, M. Poesia completa. São Paulo: Leya, 2010.

BENJAMIN, W. Obras escolhidas. Vol I. São Paulo: Brasiliense, 1987.

BENJAMIN, W. Reflexões sobre a criança, o brinquedo e a educação. São Paulo: Duas Cidades; Editora 34, 2002.

BROUGÈRE, G. Brinquedo e cultura. Revisão técnica e versão brasileira adaptada por Gisela Wajskop. 7 ed., São Paulo: Cortez, Coleção questões da nossa época, v. 43, 2008.

CERTEAU, M. A Escrita da História. Tradução de: Maria de Lourdes Menezes, Rio de Janeiro: Forense-Universitária, 1982.

CERTEAU, M. A invenção do cotidiano: artes de fazer. v.1, 4a ed. Petrópolis: Editora Vozes. Tradução de Ephraim Ferreira Alves, 1998.

CORSARO, W. A. Interpretative reproduction in children in peer cultures. Social Psychology. USA: Quarterly, 1992.

CORSARO, W. A. Sociologia da infância. Tradução de Lia Gabriele Regius Reis. $2^{\mathrm{a}}$ ed. São Paulo: Artmed, 2012.

DELEUZE, G.; GUATTARI, F. Mil platôs. Vol 4, São Paulo: Editora 34, 1997.

DELEUZE, G.; GUATTARI, F. Kafka: por uma literatura menor. Autêntica, 1996.

DIAS, S. S. Merleau-Ponty: uma concepção de infância como ser-no-mundo. In: VI Congresso LusoBrasileiro de História da Educação. Anais... Uberlândia, MG, 17 a 20 de abril de 2006. Disponível em: http://www2.faced.ufu.br/colubhe06/anais/arquivos/Silvano\%20Severino\%20Dias.htm Acesso em 29 de mai. de 2017.

DIAS, R. Nietzsche, vida como obra de arte. Rio de Janeiro: Civilização Brasileira, 2011.

GAGnEBIn, J. M. Do conceito de mímesis no pensamento de Adorno e Benjamin. São Paulo: Perspectivas, 1993.

GAGNEBIN, J. M. Sete aulas sobre linguagem, memória e história. Rio de Janeiro: Imago, 2005.

GUIMARÃES NETO, R. B. A lenda do ouro verde: política de colonização no Brasil contemporâneo. Cuiabá: Unicen, 2002.

JOANONI NETO, V. Um pouco da História do Brasil na ditadura: Narrativas sobre a migração para áreas de fronteira e a presença da Igreja no Mato Grosso após 1970. Anais... VII Encontro Regional de História da Anpuh-MT. UFMT, Rondonópolis, 2012.

MATURANA, H. R.; VERDEN-ZÖLLER, G. Amar e brincar: Fundamentos esquecidos do humanoDo patriarcado à democracia. Tradução de Humberto Mariotti e Lia Diskin. São Paulo: Palas Athena, 2004.

MERLEAU-PONTY, M. Fenomenologia da percepção. Tradução C, Moura. São Paulo: Martins Fontes, 1994.

MERLEAU-PONTY, M. O visível e o invisível. Tradução J. A. Gianotti e A. Mora d'Oliveira. São Paulo: Perspectiva, 1999.

MÜLLER, A. Conversa de poesia, exercício de prosa. Manoel de Barros. Rio de Janeiro: Beco do Azougue, 2010.

NIETZSCHE, F. W. A gaia ciência. Tradução, notas e posfácio Paulo César de Souza. São Paulo: Companhia das Letras, 2001. 
PANOSSO NETTO, A. Vera - a princesinha do Nortão: uma contribuição ao estudo da ocupação da Amazônia mato-grossense. Campo Grande, MS: Impressão Gráfica União-Rondonópolis, MT, 2000.

PESAVENTO, S. Crônica: A leitura sensível do Tempo. In: Anos 90 - Revista do Programa de PósGraduação em História da Universidade Federal do Rio Grande do Sul. Porto Alegre, n. 7, julho de 1997. p. 29-37. Disponível em: http://www.seer.ufrgs.br/index.php/anos90/article/view/6184/3677. Acesso em 12 de jun. de 2016.

RESENDE-DUARTE, J. Travessias e Silêncio: uma autobiografia fenomenológica do caminhar. 2019, 226f. Tese (Doutorado em Educação) - Programa de Pós-Graduação em Educação, Cuiabá: UFMT.

ROHDEN, J. B. A reinvenção da escola: histórias, memórias e práticas e educativas no período colonizatório de Sinop-MT (1973-1979). Cuiabá: EdUFMT, 2016.

ROHDEN, J. B. Memórias Crianceiras e seus despropósitos: uma investigação histórico-poética do brincar-bricoleur de meninos e meninas do/no m/Mato. 2019. Tese (Doutorado em Educação). Universidade Federal de Mato Grosso, UFMT: Programa de Pós-Graduação em Educação, PPGE. Cuiabá: UFMT, 2019.

SANCHES, E. O. As infâncias de Benjamin, uma possibilidade de experiência com o moderno. Educação e Filosofia, v. 31, n. 61, 2017. Disponível em: http://www.seer.ufu.br/index.php/EducacaoFilosofia/ article/view/27699. Acesso em 29 de mai. de 2017.

SANTOS, J. C. Parecer (07/07/2017) - Parecer de Qualificação da Tese Intitulada: Memórias crianceiras e seus despropósitos: uma investigação Histórico-poética do brincar-bricoleur de meninos e meninas do/no m/Mato. Doutoranda Josiane Brolo Rohden apresentada ao Programa de Pós-Graduação em Educação/PPGE/UFMT em Cuiabá, MT, Instituto de Educação, Sinop, UNEMAT, 2017.

SANTOS, E. D. N. Manoel de Barros: peregrinação da poesia por um conhecimento natural. Dissertação de Mestrado (Mestrado em Estudos da Literatura) 222f., Niterói, RJ: UFF, 2015. Disponível em: http:// www.repositorio.uff.br/jspui/handle/1/3094. Acesso em 29 de mai. de 2017.

SARMENTO, M. J. Imaginário e culturas da infância. Cadernos de Educação, Pelotas, v. 12, n. 21, p. 51-69, 2003.

STRECK, D. R. Parecer (07/07/2017) - Parecer de Qualificação da Tese Intitulada: Memórias crianceiras e seus despropósitos: uma investigação Histórico-poética do brincar-bricoleur de meninos e meninas do/no m/Mato. Doutoranda Josiane Brolo Rohden apresentada ao Programa de Pós-Graduação em Educação/PPGE/UFMT em Cuiabá, MT, Instituto de Educação, Sinop, UFMT, 2017. 